Ramírez García, Antonia; Muñoz Fernández, Ma del Carmen (2012). Prácticas inclusivas de los docentes en la convivencia escolar y en la organización y funcionamiento de los centros de educación primaria de la zona norte de Córdoba. Revista de Investigación Educativa, 30 (1), 197-222.

\title{
PRÁCTICAS INCLUSIVAS DE LOS DOCENTES EN LA CONVIVENCIA ESCOLARY EN LA ORGANIZACIÓN Y FUNCIONAMIENTO DE LOS CENTROS DE EDUCACIÓN PRIMARIA DE LA ZONA NORTE DE CÓRDOBA
}

\author{
Antonia Ramírez García \\ Facultad de Ciencias de la Educación. Universidad de Córdoba \\ $M^{a}$ del Carmen Muñoz Fernández \\ Servicio de Inspección Educativa de la Delegación Provincial de Córdoba
}

\section{RESUMEN}

Este trabajo presenta una investigación que indaga sobre las prácticas inclusivas de los docentes de educación primaria en los colegios de la zona norte de Córdoba. Los objetivos planteados son: identificar las prácticas inclusivas que favorecen la convivencia en los centros y conocer si la organización y el funcionamiento de los centros están al servicio de aprendizajes inclusivos o no. Las hipótesis se centran en determinar si las características del profesorado — sexo, edad, tiempo de servicio, especialidad, lugar de trabajo, cargo ocupado y tutorización-inciden en las prácticas inclusivas en las dimensiones convivencia y organización y funcionamiento del centro, ambas foco de atención de la Actuación Prioritaria de la Inspección Educativa en Andalucía durante 2009/10. En la investigación participaron 173 sujetos a los que se les aplicó un cuestionario (escala Likert) adaptado del Index for Inclusion tras su correspondiente pilotaje, destacando la existencia de diferencias significativas entre las características de los docentes y las dimensiones propuestas.

Palabras clave: Educación inclusiva; Integración; Convivencia escolar; Organización escolar.

Correspondencia:

Antonia Ramírez García (ed1ragaa@uco.es). Facultad de Ciencias de la Educación. Universidad de Córdoba. E-mail autores:

$\mathrm{M}^{\mathrm{a}}$ del Carmen Muñoz (mariac.munoz.ext@juntadeandalucia.es). 


\title{
INCLUSIVE PRACTICES OF TEACHERS IN SCHOOL COEXISTENCE AND IN THE ORGANIZATION AND FUNCTIONING OF PRIMARY EDUCATION SCHOOLS INTHE NORTH AREA OF CORDOBA (SPAIN)
}

\begin{abstract}
This paper presents a research study on inclusive practices of primary education teachers in schools in the north area of Cordoba, Spain (priority action of education inspectors in Andalusia in 2009/10). The objectives were: to identify inclusive practices that promote coexistence in schools, and to find out whether school organization and functioning are at the service of inclusive learning. Hypotheses focused on establishing whether teachers' characteristics - gender, age, working experience, subject, work place, position and tutorship - affect inclusive practices in two dimensions: coexistence and school organization and functioning. A sample of 173 participants filled in a questionnaire (Likert scale) adapted from the Index for Inclusion after piloting. Significant differences between teachers' characteristics and the proposed dimensions were identified.
\end{abstract}

Key words: Inclusive education; Integration; School coexistence; School organization.

\section{UNA APROXIMÁCIÓNTEÓRICA}

Gran parte de la sociedad opina que nuestro sistema educativo necesita cambios que propicien una mejora de los procesos de enseñanza-aprendizaje del alumnado. Pocas personas dudan de que el lugar idóneo para alcanzar este objetivo es una escuela inclusiva que acoja a todos y a todas y garantice el éxito no sólo en el acceso, sino también en el progreso y en los resultados (Booth y Ainscow, 2000). Pero, ¿de qué cambio hablamos?, ¿estaría la solución en un nivel político o cabría también pensar en la posibilidad de un cambio a nivel educativo con las innovaciones necesarias en la cultura de nuestros centros escolares?, ¿habría que dedicar mayor dotación económica a educación de tal forma que nada imprescindible quedara sin financiación? Muchas son las preguntas y diversas y complejas las respuestas que se pueden dar. A lo largo de estas páginas analizaremos algunos conceptos que posibilitan el paso de una escuela tradicional a otra inclusiva, así como algunas de las propuestas más exitosas respecto a la educación inclusiva, entre ellas la aplicación del Index for inclusión en centros educativos. Este instrumento ha constituido la base para la elaboración de un cuestionario destinado a determinar en qué elementos los colegios de la Zona Norte de Córdoba son inclusivos y en cuáles no, centrándonos de forma prioritaria en dos ámbitos: la convivencia escolar y la organización y funcionamiento de los centros, aspectos clave vinculados con la Actuación Prioritaria de la Inspección de Educación de Andalucía en el curso 2009-10.

Atención a la diversidad, integración, inclusión o educación para todos y todas son conceptos que continuamente podemos encontrar en el discurso pedagógico actual. El primero de ellos, la atención a la diversidad, surge en nuestro país a partir de la promulgación de la LOGSE (1990) con la intención de eliminar una doble vía de escolarización del alumnado, el que era considerado "normal" en centros ordinarios, y el que se identificaba como "especial" en centros específicos donde se "recluía" al 
alumnado según su discapacidad y con una respuesta sectorizada por parte de la Administración Educativa. A pesar de que la norma legal consideraba la atención a la diversidad del alumnado como punto de partida de la intervención educativa, la realidad mostraba una "seudo-integración" del alumnado que presentaba discapacidad en centros ordinarios o en "aulas específicas" dentro de ellos; sin embargo, nada alteró los distintos ámbitos de la vida escolar.

Por su parte, el concepto de integración ha sido clave en la última parte del siglo $\mathrm{XX}$, pero entendido, en la mayoría de los casos, de manera restrictiva. La labor de los profesionales de la educación se limitaba a dotar de apoyos y recursos al alumnado que los necesitaba, provocando una integración sólo formal, pero no de facto, ya que: 1) No ha habido cambios significativos en el proyecto educativo de los centros, en su organización y funcionamiento ni en sus prácticas de enseñanza (Ainscow, 2001) (citado en Echeita y Sandoval, 2002); 2) El énfasis se puso en la "diferencia" del individuo, considerando ésta como el problema al que había que darle respuesta, en vez de centrarse en las potencialidades desarrollables por la persona, lo que provocó que se consiguiera el efecto contrario: "etiquetar" y "clasificar" al alumnado en función de sus capacidades y 3) La respuesta a la integración en los centros escolares llegó desde un ámbito más "terapéutico" que "educativo".

Aunque en la primera Conferencia que se celebró en Jomtien (Tailandia) se pusieron las bases de una educación para todos, marcando un hito en la evolución de la inclusión, al ser la primera vez que los dirigentes mundiales se enfrentaron al desafío de luchar contra la exclusión educativa (Blanco, 2008), fue en 1994 cuando la Conferencia Mundial de Salamanca sobre Necesidades Educativas Especiales. Acceso y calidad (UNESCO, 1994), hizo suyo el término de inclusión, aplicado únicamente a la atención de alumnos de necesidades educativas especiales, asentando algunas bases para consolidar un cambio de perspectivas en la "educación especial".

No obstante, en la evaluación que se hizo de los diez años de Educación para Todos, se concluyó que los avances habían sido escasos, por lo que en el Foro Mundial de Educación para Todos (Dakar, 2000) los países recomendaron medidas más sistemáticas para reducir las desigualdades (Blanco, 2008).

El concepto ha ido evolucionando hasta entender que la inclusión se centra en cómo apoyar a todo el alumnado para ofrecerle un aprendizaje satisfactorio, teniendo como objetivos fundamentales garantizar el libre acceso a la educación, prestar apoyo individual y promover la integración social (Moberg, 2001). Por su parte, Watkins (2007) considera que este término se amplía a un alumnado con posibilidad de exclusión y no sólo a aquellos que presentan necesidades educativas especiales. En este sentido, Ainscow y Miles (2008) destacan que la inclusión conlleva una reestructuración de las culturas, las políticas y las prácticas en las escuelas. Sin embargo, también existen reticencias ante esta nueva filosofía (Fuchs y Fuchs, 1994, Brantlinger, 1997; Freire y César, 2002) (citados en en Ainscow y Miles, 2008) que pretende responder a la diversidad desde la valoración que hace de todos los miembros de la comunidad, su apertura a nuevas ideas y la consideración de la diferencia de forma digna (Arnaiz, 2000).

Bien es cierto que avanzar hacia la inclusión en los centros educativos origina serias dificultades, incluso existe todo un corpus de documentación crítica en el que se destacan los problemas y las complejidades puestas de manifiesto cuando las escuelas 
intentan alcanzar un mayor grado de inclusión (Dyson y Millward, 2000). No obstante, la preocupación de organismos internacionales como la UNESCO, la Convención sobre los derechos de las personas con discapacidad de la Organización de Naciones Unidas (2006), la Agencia Europea para el Desarrollo de la Educación del Alumnado con Necesidades Educativas Especiales o la OCDE, por el tema han generado diversas investigaciones sobre aspectos colaterales de la educación inclusiva que apoyan la urgencia de dirigirnos hacia una escuela inclusiva.

$\mathrm{Al}$ mismo tiempo, autores de distintos países han profundizado en este ámbito de la educación inclusiva, lo que supone un progreso importante en las actuaciones aplicables en los centros educativos; entre ellos cabría citar a Booth y Ainscow en 2000 con la publicación del Index For Inclusion o a Wehmeyer (2009), quien invita a diseñar verdaderos apoyos generalizados en lugar de crear programas para alumnos "etiquetados; Hlinen y Järvinen (2008) muestran el éxito del vínculo existente entre educación inclusiva y aprendizaje cooperativo y participación del alumnado, docentes y comunidad escolar; por su parte, Almeida y Alberte (2009) destacan la necesidad de establecer un diálogo entre el proceso de investigación y formación para mejorar las prácticas inclusivas. Finalmente, destacar las aportaciones de Canadá en el establecimiento de niveles de inclusión en diferentes ámbitos (ver figura 1).

\begin{tabular}{|c|c|}
\hline \multirow{4}{*}{$\begin{array}{c}\text { Primer nivel: } \\
\text { Factores sociales }\end{array}$} & Opinión pública \\
\hline & Políticas sociales \\
\hline & Asociaciones comunitarias \\
\hline & Familias \\
\hline \multirow{5}{*}{$\begin{array}{l}\text { Segundo nivel: } \\
\text { El sistema educativo }\end{array}$} & $\begin{array}{l}\text { Liderazgo político y administrativo en el desarrollo de una } \\
\text { educación inclusiva }\end{array}$ \\
\hline & Formación sobre inclusión \\
\hline & Actitud del profesorado \\
\hline & Planes de transición entre etapas y centros \\
\hline & Financiación \\
\hline \multirow{5}{*}{$\begin{array}{l}\text { Tercer nivel: } \\
\text { El Centro }\end{array}$} & Organización y funcionamiento de los apoyos \\
\hline & Clima de convivencia y sentido de comunidad \\
\hline & Apertura y participación \\
\hline & Recursos y accesibilidad \\
\hline & El rol del profesorado ordinario y el de los especialistas \\
\hline \multirow{2}{*}{ Cuarto nivel: Aula } & Clima de aula \\
\hline & Metodología didáctica \\
\hline
\end{tabular}

FIGURA 1

NIVELES DE INCLUSIÓN

Elaboración propia. Tomado de Moliner García (2008). 
En nuestro país el principio de inclusión se recoge por primera vez en la LOCE (2002) y se desarrolla con la LOE (2006). Esta normativa, dado el carácter descentralizado del sistema educativo, es concretada en cada Comunidad Autónoma; en el caso de Andalucía es la Orden de 25 de julio de 2008 la que recoge el testigo y desarrolla dicho principio. Junto a la normativa se han realizado diferentes experiencias en torno a la eliminación de "barreras" que impiden el acceso al aprendizaje de todo el alumnado (Booth y Ainscow, 2000), entre ellas la aplicación del Index for inclusión en determinadas comunidades autónomas como herramienta para identificar e intentar resolver las dificultades que aparecen en los centros en torno a la inclusión de todo el alumnado.

Desde diferentes sectores educativos se plantea la necesidad de aplicar el Index en los centros escolares; al mismo tiempo, la Actuación Prioritaria de la Inspección de Educación de Andalucía en el curso 2009-10 ("Intervención de la Inspección en una muestra de centros escolares para asesorar, evaluar y supervisar aquellas dimensiones básicas de los mismos que contribuyan a la mejora de los resultados y rendimientos escolares") ha seleccionado varios aspectos de análisis, coincidentes con algunos de los ámbitos del tercer nivel de inclusión canadiense, entre ellos la convivencia escolar y la organización y funcionamiento de los centros como elementos que facilitan o dificultan los resultados escolares del alumnado que desarrolla su proceso de enseñanza y aprendizaje en un colegio y que son necesarios analizar antes de "comenzar a caminar hacia una educación inclusiva" (Moriña, 2008: 524). Asimismo, profundizando en esta misma línea Moriña (2008: 523) recoge las aportaciones de Pijl, Meijer y Hegarty (1997) respecto a las tres dimensiones que se pueden distinguir cuando un centro educativo desarrolla procesos de mejora o prácticas de inclusión: "condiciones externas a los centros, características y condiciones organizativas de los mismos (...) y condiciones organizativas, didácticas y sociales de las aulas. En este marco de referencia, pues, se sitúa la investigación llevada a cabo y presentada en estas páginas.

\section{NUESTROS OBJETIVOS E INTERROGANTES}

Esta investigación se propone indagar sobre las prácticas inclusivas de los docentes de educación primaria en los colegios de la zona norte de la provincia de Córdoba - capital y provincia-. Para ello nos planteamos dos objetivos:

1. Identificar las prácticas inclusivas que maestros y maestras de educación primaria llevan a cabo en sus centros de trabajo para favorecer la convivencia entre los diferentes miembros que componen la comunidad educativa de los colegios de educación infantil y primaria.

2. Conocer si la organización y el funcionamiento de los colegios de educación infantil y primaria se encuentran al servicio de aprendizajes inclusivos o, por el contrario, suponen una fuente de exclusión para el alumnado y sus familias.

En función de los objetivos nos propusimos dar respuesta al siguiente interrogante: ¿Influye el perfil de los docentes de la etapa de educación infantil y primaria de la zona norte de Córdoba tanto en las prácticas puestas en marcha en sus centros para favorecer la convivencia entre sus miembros, como en una organización y funcionamiento de los colegios basada en la inclusividad? 


\section{METODOLOGÍA DE LA INVESTIGACIÓN}

A lo largo del proceso metodológico se han seguido una serie de fases: planteamiento del problema de investigación, delimitación de los objetivos del estudio, formulación de interrogantes, identificación y denominación de variables, diseño de la investigación, descripción de la muestra, delimitación del instrumento de recogida de información y estrategias de análisis de datos.

Las tres primeras ya han sido comentadas con anterioridad, respecto a las variables de estudio, la figura 2 muestra las variables independientes que se tuvieron en consideración y la figura 3 recoge las variables dependientes de la investigación.

\begin{tabular}{|c|c|}
\hline Variables & Categorías \\
\hline 1. Sexo & $\begin{array}{l}\text { 1. Mujer } \\
\text { 2. hombre }\end{array}$ \\
\hline 2. Edad & $\begin{array}{l}\text { 1. } 21 \text { a } 25 \text { años } \\
\text { 2. } 26 \text { a } 30 \text { años } \\
\text { 3. } 31 \text { a } 40 \text { años } \\
\text { 4. } 41 \text { a } 50 \text { años } \\
\text { 5. } 51 \text { a } 60 \text { años } \\
\text { 6. Más de } 60 \text { años }\end{array}$ \\
\hline 3. Tiempo de servicio & $\begin{array}{l}\text { 1. Menos de } 1 \text { año } \\
\text { 2. } 1 \text { a } 5 \text { años } \\
\text { 3. } 6 \text { a } 10 \text { años } \\
\text { 4. } 11 \text { a } 20 \text { años } \\
\text { 5. } 21 \text { a } 30 \text { años } \\
\text { 6. Más de } 30 \text { años }\end{array}$ \\
\hline 4. Especialidad & $\begin{array}{l}\text { 1. Educación Primaria } \\
\text { 2. Lengua Extranjera } \\
\text { 3. Educación Infantil } \\
\text { 4. Educación Física } \\
\text { 5. Pedagogía Terapéutica } \\
\text { 6. Educación Musical } \\
\text { 7. Audición y lenguaje }\end{array}$ \\
\hline 5. Cargo ocupado & $\begin{array}{l}\text { 1. Miembro del equipo directivo } \\
\text { 2. Coodinación de ciclo } \\
\text { 3. Coordinación de proyectos } \\
\text { 4. Sin cargo }\end{array}$ \\
\hline 6. Tutorización & $\begin{array}{l}\text { 1. Tutor/a } \\
\text { 2. No tutor/a }\end{array}$ \\
\hline
\end{tabular}

Elaboración propia. 


\begin{tabular}{|c|c|c|}
\hline Dimensiones & Variables & Indicadores \\
\hline \multirow{8}{*}{ Convivencia } & $\begin{array}{l}\text { Existencia de actos de } \\
\text { acogida }\end{array}$ & $\begin{array}{l}\text { - Actos sociales de bienvenida al alumnado } \\
\text { - Actos sociales de bienvenida al profesorado } \\
\text { - Actos sociales de bienvenida a las familias } \\
\text { - Actos sociales de bienvenida al personal de } \\
\text { administración y servicios }\end{array}$ \\
\hline & $\begin{array}{l}\text { Existencia de actos de } \\
\text { despedida }\end{array}$ & $\begin{array}{l}\text { - Actos sociales de despedida al alumnado } \\
\text { - Actos sociales de despedida al profesorado } \\
\text { - Actos sociales de despedida a las familias } \\
\text { - Actos sociales de despedida al personal de ad- } \\
\text { ministración y servicios }\end{array}$ \\
\hline & $\begin{array}{l}\text { Conocimiento inter- } \\
\text { cultural }\end{array}$ & $\begin{array}{l}\text { - Realización de actividades de conocimiento de } \\
\text { diferentes culturas con las familias }\end{array}$ \\
\hline & $\begin{array}{l}\text { Vinculación con la co- } \\
\text { munidad }\end{array}$ & - Implicación en actividades de la comunidad \\
\hline & $\begin{array}{l}\text { Percepción del profe- } \\
\text { sorado sobre el senti- } \\
\text { miento de pertenencia } \\
\text { al centro educativo }\end{array}$ & $\begin{array}{l}\text { - Constatación fehaciente de la adaptación del } \\
\text { alumnado a la vida del centro } \\
\text { - Sentimiento de pertenencia al centro por parte } \\
\text { del alumnado } \\
\text { - Sentimiento de pertenencia al centro por parte } \\
\text { del profesorado } \\
\text { - Sentimiento de pertenencia al centro por parte de } \\
\text { las familias } \\
\text { - Sentimiento de pertenencia al centro por parte } \\
\text { del personal no docente }\end{array}$ \\
\hline & $\begin{array}{l}\text { Empleo de fórmulas } \\
\text { de cortesía }\end{array}$ & $\begin{array}{l}\text { - Saludos y despedidas por parte de los miembros } \\
\text { de la comunidad educativa }\end{array}$ \\
\hline & $\begin{array}{l}\text { Uso de recursos que } \\
\text { facilitan las relaciones }\end{array}$ & $\begin{array}{l}\text { - Símbolos, documentos del centro en distinto } \\
\text { idioma y/o pictogramas que favorecen la comu- } \\
\text { nicación }\end{array}$ \\
\hline & $\begin{array}{l}\text { Problemas de con- } \\
\text { ducta }\end{array}$ & $\begin{array}{l}\text { - Utilización de estrategias previas a la sanción } \\
\text { - Continuidad del aprendizaje a pesar de la } \\
\text { expulsión } \\
\text { - Conocimiento de causas que generan problemas } \\
\text { de convivencia } \\
\text { - Corresponsabilidad docente en la corrección de } \\
\text { conductas } \\
\text { - Participación del alumnado en la creación de es- } \\
\text { trategias preventivas y paliativas } \\
\text { - Aceptación de las normas de convivencia por } \\
\text { parte de las familias }\end{array}$ \\
\hline
\end{tabular}




\begin{tabular}{|c|c|c|}
\hline Dimensiones & Variables & Indicadores \\
\hline \multirow{9}{*}{$\begin{array}{l}\text { Organización } \\
\text { y funciona- } \\
\text { miento }\end{array}$} & $\begin{array}{l}\text { Cauces de informa- } \\
\text { ción }\end{array}$ & $\begin{array}{l}\text { - Conocimiento de la normativa por parte del pro- } \\
\text { fesorado } \\
\text { - Facilitación de información al profesorado recién } \\
\text { llegado } \\
\text { - Establecimiento de cauces de información sobre } \\
\text { formación permanente }\end{array}$ \\
\hline & $\begin{array}{l}\text { Organización del es- } \\
\text { pacio }\end{array}$ & $\begin{array}{l}\text { - Eliminación de barreras arquitectónicas } \\
\text { - Asunción de criterios comunes en la organización } \\
\text { espacial de las aulas }\end{array}$ \\
\hline & $\begin{array}{l}\text { Organización del } \\
\text { tiempo }\end{array}$ & $\begin{array}{l}\text { - Empleo de criterios pedagógicos para elaborar } \\
\text { horarios }\end{array}$ \\
\hline & Agrupamientos & $\begin{array}{l}\text { - Empleo de criterios aleatorios en la configuración } \\
\text { de grupos } \\
\text { - Concepción sobre los agrupamientos flexibles }\end{array}$ \\
\hline & $\begin{array}{l}\text { Participación de la co- } \\
\text { munidad educativa }\end{array}$ & $\begin{array}{l}\text { - Fomento de la participación desde el equipo di- } \\
\text { rectivo } \\
\text { - Facilitación de información a las familias en su } \\
\text { lengua materna } \\
\text { - Disponibilidad de oportunidades de participa- } \\
\text { ción de las familias }\end{array}$ \\
\hline & Coordinación docente & - Existencia de coordinación entre etapas \\
\hline & $\begin{array}{l}\text { Actividades extraes- } \\
\text { colares }\end{array}$ & $\begin{array}{l}\text { - Existencia de una amplia oferta de actividades } \\
\text { para todo el alumnado }\end{array}$ \\
\hline & $\begin{array}{l}\text { Medidas de reintegra- } \\
\text { ción }\end{array}$ & $\begin{array}{l}\text { - Reintegración del alumnado expulsado por mo- } \\
\text { tivos de disciplina }\end{array}$ \\
\hline & Objetivo & $\begin{array}{l}\text { - Organización del centro en función de la mejora } \\
\text { del aprendizaje }\end{array}$ \\
\hline
\end{tabular}

\section{FIGURA 3 \\ VARIABLES DE ESTUDIO DEPENDIENTES}

Elaboración propia.

En lo que concierne a la investigación, ésta sigue un diseño empírico, no experimental, descriptivo y correlacional, al tiempo que se sustenta en un estudio tipo encuesta.

Respecto a los participantes en la misma, una vez obtenido el total de la población (N=606), siguiendo a Arkin y Colton (1962) establecimos una muestra significativa de 173 sujetos $( \pm 4)$, la distribución de la misma queda recogida en la figura 4 .

La muestra, pues, la componen en su mayoría mujeres, con un 65,9\% de presencia frente a un $34,1 \%$ de hombres. En cuanto a la edad de la misma existe un porcentaje mayoritario de docentes con edades comprendidas entre 41 y 50 años $(30,1 \%)$, seguido del profesorado que ocupa intervalos de edad entre 21 y 30 años $(27,1 \%)$ y mayores de 51 años $(23,2 \%)$. 


\begin{tabular}{|c|c|c|}
\hline \multicolumn{2}{|c|}{ Distribución de la muestra } & \multirow{2}{*}{$\begin{array}{r}\mathbf{N} \\
11 \\
\end{array}$} \\
\hline En función dol coro & Mujer & \\
\hline En runcion ael sexo & Hombre & 59 \\
\hline \multirow{4}{*}{ En función de la edad } & De 21 a 30 años & 47 \\
\hline & De 31 a 40 años & 34 \\
\hline & De 41 a 50 años & 52 \\
\hline & Más de 51 años & 40 \\
\hline \multirow{4}{*}{ En función del tiempo de servicio } & Hasta 10 años & 73 \\
\hline & Entre 11 y 20 años & 38 \\
\hline & Entre 21 y 30 años & 25 \\
\hline & Más de 30 años & 37 \\
\hline \multirow{2}{*}{ En función del lugar de trabajo } & Capital & 61 \\
\hline & Provincia & 112 \\
\hline \multirow{6}{*}{ En función de la especialidad } & Educación Primaria & 78 \\
\hline & Lengua Extranjera & 15 \\
\hline & Educación Infantil & 43 \\
\hline & Educación Física & 16 \\
\hline & Educación Musical & 11 \\
\hline & Educación Especial (PT y AL) & 10 \\
\hline \multirow{4}{*}{ En función de la ocupación de un cargo } & Equipo Directivo & 26 \\
\hline & Coordinación de ciclo & 42 \\
\hline & Coordinación de proyectos & 21 \\
\hline & Sin cargos & 84 \\
\hline \multirow{2}{*}{ En función del ejercicio de la tutoría } & Tutorización & 121 \\
\hline & No tutorización & 52 \\
\hline
\end{tabular}

FIGURA 4

DISTRIBUCIÓN DE LA MUESTRA

Elaboración propia.

En relación al tiempo de servicio es el profesorado que ha ejercido docencia hasta 10 años el que obtiene un mayor porcentaje $(42,1 \%)$, seguido del que ha estado trabajando entre 11 y 20 años (22\%), del profesorado con un tiempo de experiencia mayor de 30 años $(21,4 \%)$ y, finalmente, de los docentes con un tiempo de servicio entre 21 y 30 años $(14,5 \%)$. Respecto a la especialidad de los docentes, destaca la especialidad de educación primaria $(45,1 \%)$, educación infantil $(24,9 \%)$, seguida de educación física 
$(9,2 \%)$, lengua extranjera $(8,7 \%)$, educación musical (6,4\%) siendo educación especial (pedagogía terapéutica y audición y lenguaje) la que ocupa la última posición (5,7\%).

La distribución de la muestra en cuanto a la ocupación o no de un cargo durante el curso académico en estudio ha quedado establecido del siguiente modo: miembro del equipo directivo (15\%), coordinación de ciclo $(24,3 \%)$, coordinación de Proyectos $(12,1 \%)$ y sin cargo $(48,6 \%)$. Asimismo, los docentes de la muestra que han ocupado tutorías durante el presente curso han sido de un $69,9 \%$, frente a un $30,1 \%$ que no lo han hecho.

El instrumento que se ha empleado es un cuestionario elaborado ad hoc para la investigación, partiendo del Index for inclusión diseñado por Booth y Ainscow (2000) (ver anexo 1). La contextualización al entorno de aplicación ha seguido varias fases: 1) Elaboración de un cuestionario provisional sobre las dos dimensiones de interés -convivencia y organización y funcionamiento de los centros educativos-, 2) Presentación del cuestionario a expertos — docentes universitarios y no universitarios-para valorar su pertinencia e idoneidad, 3) Elaboración de un segundo cuestionario con las aportaciones realizadas por los expertos, 4) Pilotaje del cuestionario en 20 maestros y maestras de la Zona Norte de Córdoba, 5) Determinación de la fiabilidad del cuestionario para constatar su coherencia interna y el grado de estabilidad de las respuestas. Para estimar la fiabilidad del cuestionario se implementó la prueba de consistencia interna Alfa de Crombach, obteniendo un coeficiente medio de 0.974 , lo que evidenció garantías científicas para su posterior aplicación. Asimismo, se realizó un análisis factorial y de contenido; en este sentido, los ítems que no discriminaron se eliminaron y/o redactaron de nuevo. El Alfa de Crombach tras la aplicación final a la muestra fue de 0.938 , 6) Elaboración definitiva del cuestionario, que contó con tres apartados: introducción, datos descriptivos de identificación de los sujetos (sexo, edad, tiempo de servicio, lugar de trabajo, especialidad, cargo ocupado y tutorización) y detección de las prácticas inclusivas de los docentes en torno a las dos dimensiones mencionadas, a partir de una escala de medición tipo Likert (1 a 5) compuesta por 45 ítems.

El análisis de datos llevado a cabo comenzó con un análisis descriptivo de las diferentes variables, calculando su distribución de frecuencias, estadísticos de tendencia central como la media y medidas de dispersión como la desviación típica. En un segundo momento se realizó un análisis comparativo o inferencial de estos datos a través de pruebas de significación como el Análisis de la Varianza (ANOVA) tomando como referencia un valor $\leq .05$. Finalmente, utilizamos como prueba post hoc la prueba de Tukey para aquellas variables en las que se comparaban tres o más grupos. Para el tratamiento de la información se utilizó el programa de técnicas estadísticas SPSS.

\section{RESULTADOS}

Los resultados obtenidos en esta investigación, de acuerdo con las dos dimensiones analizadas, muestran valores por encima de la media; en cuanto a la desviación típica, los resultados obtenidos en la mayoría de los ítems muestran que el grupo de los 173 docentes que han respondido al cuestionario se constituye como un grupo bastante homogéneo en cuanto a sus manifestaciones. 


\section{I. Prácticas inclusivas en la convivencia escolar}

En esta dimensión se analizaron aquellas prácticas llevadas a cabo por los docentes del centro escolar respecto a la convivencia que favorecen la inclusión de los distintos miembros de la comunidad educativa en la vida cotidiana del centro (ver tabla 1).

TABLA 1

PRÁCTICAS INCLUSIVAS EN LA CONVIVENCIA ESCOLAR

\begin{tabular}{|l|c|c|c|}
\hline \multicolumn{1}{|c|}{ Prácticas inclusivas en la convivencia escolar } & Media & $\begin{array}{c}\text { Desviación } \\
\text { típica }\end{array}$ & N \\
\hline 1. Actos de bienvenida al alumnado & 3,62 & 1,403 & 173 \\
\hline 2. Actos de despedida al alumnado & 4,24 & 1,103 & 173 \\
\hline 3. Actos de bienvenida al profesorado & 3,16 & 1,403 & 173 \\
\hline 4. Actos de despedida al profesorado & 3,88 & 1,311 & 173 \\
\hline 5. Actos de bienvenida a las familias & 3,29 & 1,621 & 173 \\
\hline 6. Actos de despedida a las familias & 3,41 & 1,920 & 173 \\
\hline 7. Actos de bienvenida a personal no docente & 2,84 & 1,972 & 173 \\
\hline 8. Actos de despedida al personal no docente & 3,27 & 2,218 & 173 \\
\hline 9. Actividades culturales & 3,72 & 2,363 & 173 \\
\hline 10. Actuaciones del centro con el entorno & 4,1 & 1,201 & 173 \\
\hline 11. Comprobación de la satisfacción del alumnado & 4,23 & 0,942 & 173 \\
\hline 12. Sentimientos de pertenencia del alumnado al centro & 4,32 & 0,926 & 173 \\
\hline 13. Sentimientos de pertenencia del profesorado & 4,2 & 1,265 & 173 \\
\hline 14. Sentimientos de pertenencia de las familias & 4,28 & 1,433 & 173 \\
\hline 15. Sentimientos de pertenencia del personal no docente & 4,5 & 1,707 & 173 \\
\hline 16. Empleo de fórmulas de cortesía & 4,31 & 0,853 & 173 \\
\hline 17. Empleo de símbolos & 4,15 & 1,938 & 173 \\
\hline 18. Uso de estrategias a la expulsión & 4,03 & 1,555 & 173 \\
\hline 19. Continuación del aprendizaje & 4,55 & 1,545 & 173 \\
\hline 20. Se tiene en cuenta la baja autoestima del alumnado & 4,32 & 0,901 & 173 \\
\hline 21. Corrección conjunta de conductas inapropiadas & 4,13 & 0.908 & 173 \\
\hline 22. Alumnado crea estrategias & 3,94 & 0,881 & 173 \\
\hline 23. Familias están de acuerdo con las normas de convivencia & 4,32 & 1,307 & 173 \\
\hline
\end{tabular}

Fuente: Elaboración propia.

En esta dimensión sobre prácticas inclusivas detectadas en la convivencia escolar se puede observar cómo las valoraciones están por encima de la media. 
Se puede resaltar el ítem $19\left(\overline{\mathrm{X}}=4^{\prime} 55\right)$ en el centro se considera que a pesar de la expulsión el alumno puede continuar su aprendizaje, que presenta el valor más alto, pudiéndose interpretar que en los centros de educación primaria de la Zona Norte de Córdoba el número de expulsiones no es significativo. El profesorado estima, además, que en el caso de que se expulsase a los alumnos no habría problema en que estos siguieran con su ritmo normal de aprendizaje.

TABLA 2

ANÁLISIS DE VARIANZA DE LAS VARIABLES SEXO, LUGAR DE TRABAJO Y TUTORIZACIÓN. DIMENSIÓN CONVIVENCIA ESCOLAR

\begin{tabular}{|l|r|r|r|r|r|r|}
\hline \multirow{2}{*}{ Prácticas inclusivas en la convivencia escolar } & \multicolumn{2}{|c|}{ Sexo } & \multicolumn{2}{c|}{ Lugar de trabajo } & \multicolumn{2}{c|}{ Tutorización } \\
\cline { 2 - 7 } & \multicolumn{1}{|c|}{ F } & \multicolumn{1}{c|}{ Sig } & \multicolumn{1}{c|}{ F } & \multicolumn{1}{c|}{ Sig } & \multicolumn{1}{c|}{ F } & \multicolumn{1}{c|}{ Sig } \\
\hline 1. Actos de bienvenida al alumnado &, 348 &, 556 &, 614 &, 434 &, 286 &, 593 \\
\hline 2. Actos de despedida al alumnado &, 764 &, 383 & 2,802 &, 096 & 2,130 &, 146 \\
\hline 3. Actos de bienvenida al profesorado & 1,254 &, 264 &, 159 &, 691 &, 660 &, 418 \\
\hline 4. Actos de despedida al profesorado & 1,760 &, 186 & 13,323 &, 000 & 1,021 &, 314 \\
\hline 5. Actos de bienvenida a las familias & 1,561 &, 213 & 1,630 &, 203 &, 464 &, 497 \\
\hline 6. Actos de despedida a las familias &, 100 &, 753 &, 691 &, 407 &, 161 &, 689 \\
\hline 7. Actos de bienvenida al personal no docente &, 986 &, 322 & 1,185 &, 278 & 1,621 &, 205 \\
\hline 8. Actos de despedida al personal no docente & 4,166 &, 043 &, 948 &, 332 & 2,700 &, 102 \\
\hline 9. Actividades culturales &, 132 &, 717 &, 294 &, 588 & 1,025 &, 313 \\
\hline 10. Actuaciones del centro con el entorno &, 023 &, 880 & 3,166 &, 077 &, 048 &, 827 \\
\hline 11. Comprobación de la satisfacción del alumnado &, 053 &, 818 & 8,494 &, 004 & 3,824 &, 052 \\
\hline 12. Sentimientos de pertenencia del alumnado al centro &, 017 &, 896 & 9,611 &, 002 &, 398 &, 529 \\
\hline 13. Sentimientos de pertenencia del profesorado &, 310 &, 578 & 1,287 &, 258 & 2,177 &, 142 \\
\hline 14. Sentimientos de pertenencia de las familias &, 092 &, 763 & 9,229 &, 003 & 1,269 &, 261 \\
\hline 15. Sentimientos de pertenencia del personal no docente & 1,005 &, 318 &, 653 &, 420 & 2,705 &, 102 \\
\hline 16. Empleo de fórmulas de cortesía &, 453 &, 502 & 6,016 &, 015 & 1,987 &, 160 \\
\hline 17. Empleo de símbolos &, 067 &, 796 & 3,893 &, 050 & 1,203 &, 274 \\
\hline 18. Uso de estrategias a la expulsión &, 012 &, 914 &, 249 &, 619 &, 164 &, 686 \\
\hline 19. Continuación del aprendizaje & 1,453 &, 230 &, 320 &, 572 &, 238 &, 626 \\
\hline 20. Se tiene en cuenta la baja autoestima del alumnado &, 018 &, 893 & 2,331 &, 129 &, 073 &, 788 \\
\hline 21. Corrección conjunta de conductas inapropiadas &, 105 &, 746 & 6,096 &, 015 &, 282 &, 596 \\
\hline 22. Alumnado crea estrategias &, 011 &, 915 & 5,248 &, 023 & 6,165 &, 014 \\
\hline 23. Familias están de acuerdo con las normas de convivencia &, 523 &, 471 & 3,984 &, 048 &, 128 &, 720 \\
\hline
\end{tabular}

Fuente: Elaboración propia. 
Le siguen los ítems 12 ( $\left.\overline{\mathrm{X}}=4^{\prime} 32\right), 20\left(\overline{\mathrm{X}}=4^{\prime} 32\right)$ y $23\left(\overline{\mathrm{X}}=4^{\prime} 32\right)$; en este sentido, el ítem 12, el alumnado siente que es parte del centro educativo, no resulta sorprendente, ya que los alumnos y alumnas de educación primaria sienten la escuela como la continuación del hogar, se sienten queridos y seguros.

En cuanto al ítem 20, los docentes tienen en cuenta que la baja autoestima de los alumnos y la insatisfacción de estos puede ocasionar problemas de conducta, se puede interpretar que es algo totalmente asumido por los maestros y las maestras como así lo corrobora también la desviación típica (0'901).

El ítem 23, las familias están de acuerdo con el profesorado con las normas establecidas en el Plan de Convivencia, viene a demostrarnos que en educación primaria el profesorado trabaja conjuntamente con las familias, más que en otras etapas educativas.

Tras realizar un Análisis de Varianza para las variables sexo, lugar de trabajo y tutorización se obtuvieron los resultados recogidos en la tabla 2.

Respecto a la variable sexo podemos señalar que hemos hallado diferencias significativas en la consideración que tienen los docentes sobre la existencia de actos de despedida al personal no docente $(\mathrm{F}=4.166, \mathrm{p}=0.043)$; en este sentido, el profesorado masculino ( $\overline{\mathrm{X}}=3.75$ ) es quien opina que estos actos se llevan a cabo en mayor medida que el profesorado femenino $(\bar{X}=3.03)$.

En lo que concierne a la variable lugar de trabajo hemos encontrado diferencias estadísticamente significativas en los siguientes ítems:

- Ítem 4. En el centro hay actos sociales para despedir al profesorado $(\mathrm{F}=13.323, \mathrm{p}=0.000)$. Los docentes que ejercen en la capital $(\bar{X}=4.36)$ son los que obtienen una media mayor en esta afirmación frente a los que trabajan en la provincia $(\bar{X}=3.63)$.

- Ítem 11. Se constata que después de varias semanas el alumnado de nuevo ingreso se siente a gusto en el centro $(\mathrm{F}=8.494, \mathrm{p}=0.004)$. El profesorado de la capital $(\overline{\mathrm{X}}=4.51)$, frente al de la provincia $(\bar{X}=4.08)$ es quien más se asegura que el alumnado se sienta bien en su centro.

- Ítem 12. El alumnado siente que es parte del centro educativo ( $\mathrm{F}=9.611, \mathrm{p}=0.002)$. Nuevamente los maestros y maestras de la capital $(\bar{X}=4.61)$, frente a los de la provincia $(\bar{X}=4.16)$, son los que consideran en mayor medida la sensación de pertenencia al centro por parte del alumnado.

- Ítem 14. Las familias sienten que son parte del centro educativo $(\mathrm{F}=9.229, \mathrm{p}=0.003)$. De igual forma, los docentes de la capital $(\overline{\mathrm{X}}=4.72)$ constatan la afirmación del ítem en mayor medida que el profesorado que trabaja en la provincia $(\bar{X}=4.04)$.

- Ítem 16. Los distintos sectores de la comunidad educativa se saludan y despiden diariamente utilizando fórmulas de cortesía $(\mathrm{F}=6.016, \mathrm{p}=0.015)$. Los maestros y maestras de la capital obtienen una media superior $(\bar{X}=4.52)$ a los de la provincia $(\bar{X}$ $=4.20$ ) al opinar sobre los saludos cotidianos de la comunidad educativa.

- Ítem 17. El centro tiene en cuenta las culturas locales y los colectivos de inmigración en los símbolos, documentos del centro en distinto idioma y/o pictogramas que faciliten las relaciones entre sus miembros $(\mathrm{F}=3.893, \mathrm{p}=0.050)$. El profesorado de la capital $(\bar{X}=4.54)$ es quien realiza dicha afirmación de forma más contundente que el profesorado de la provincia $(\overline{\mathrm{X}}=3.94)$. 
- Ítem 21. El profesorado de forma conjunta se siente responsable en la corrección de las conductas del alumnado a través de unos criterios claros y consensuados $(\mathrm{F}=6.096$, $\mathrm{p}=0.015)$. Los docentes de la capital $(\overline{\mathrm{X}}=4.36)$, frente al de la provincia $(\overline{\mathrm{X}}=4.01)$, perciben más la corresponsabilidad de la corrección de las conductas del alumnado.

- Ítem 22. Se involucra al alumnado en la creación de estrategias para prevenir y reducir la ruptura de la convivencia $(\mathrm{F}=5.248, \mathrm{p}=0.023)$. Los maestros y maestras de la capital $(\overline{\mathrm{X}}=4.15)$ hacen más partícipes al alumnado en el diseño de estrategias para evitar la ruptura de la convivencia que los docentes de la provincia $(\overline{\mathrm{X}}$ $=3.83$ ).

- Ítem 23. Las familias están de acuerdo con el profesorado con las normas establecidas en el Plan de Convivencia $(\mathrm{F}=3.984, \mathrm{p}=0.048)$. Una vez más el profesorado de la capital $(\bar{X}=4.59)$, frente al de la provincia $(\bar{X}=4.18)$, quien manifiesta un mayor acuerdo de las familias con el profesorado en cuanto a normas de convivencia.

En cuanto a la variable tutorización, las diferencias significativas se han centrado en la consideración que tiene el profesorado sobre el grado en que se involucra al alumnado en la creación de estrategias para prevenir y reducir la ruptura de la convivencia ( $\mathrm{F}=6.165$, $\mathrm{p}=0.014)$; en este sentido, es el profesorado tutor $(\overline{\mathrm{X}}=4.05)$, frente al que no es tutor ( $\overline{\mathrm{X}}=3.69)$, quien lo manifiesta en mayor medida.

Asimismo, al realizar un Análisis de Varianza para las variables cargo, edad, especialidad y tiempo de servicio sólo hemos hallado diferencias estadísticamente significativas en la edad y el tiempo de servicio del profesorado (ver tabla 3).

En cuanto a la variable edad destacamos que las diferencias se centran en la realización de actividades en el centro educativo para conocer otras culturas que se integran en el mismo ( $\mathrm{F}=3.227, \mathrm{p}=0.024)$, la utilización en los centros de estrategias previas a la sanción disciplinaria $(\mathrm{F}=2.895, \mathrm{p}=0.037)$ y el acuerdo de las familias con las normas de convivencia del centro $(\mathrm{F}=3.275, \mathrm{p}=0.023)$.

En la primera cuestión es el profesorado mayor de 51 años $(\overline{\mathrm{X}}=4.05)$ quien manifiesta en mayor medida la existencia de actividades para el conocimiento de las distintas culturas del centro, frente al profesorado de edades comprendidas entre 21 y 30 años $(\bar{X}=3.30)$ y 41 y 50 años $(\bar{X}=3.27)$.

En el segundo caso es el profesorado más joven $(\overline{\mathrm{X}}=3.55)$ quien opina en menor medida que el profesorado de entre 31 y 40 años $(\overline{\mathrm{X}}=4.47)$ que el centro lleva a cabo estrategias previas a la sanción disciplinaria.

En el tercer aspecto los maestros y maestras mayores de 51 años $(\overline{\mathrm{X}}=4.85)$ manifiestan más contundentemente que los que tienen edades comprendidas entre 31 y 40 años $(\bar{X}=3.97)$ que las familias se encuentran de acuerdo con las normas recogidas en el Plan de Convivencia.

Respecto a la variable tiempo de servicio del docente hemos hallado ciertas diferencias significativas en la existencia de actos de bienvenida al personal no docente ( $\mathrm{F}=3.139$, $\mathrm{p}=0.027$ ), así los docentes con un tiempo de servicio comprendido entre 21 y 30 años $(\overline{\mathrm{X}}=2.12)$ no alcanzan la media de la escala, frente al profesorado con más de 30 años de servicio $(\overline{\mathrm{X}}=3.49)$, quien confirma la celebración de dichos actos. 
TABLA 3

ANÁLISIS DE VARIANZA DE LAS VARIABLES CARGO OCUPADO, EDAD, ESPECIALIDAD Y TIEMPO DE SERVICIO. DIMENSIÓN CONVIVENCIA ESCOLAR

\begin{tabular}{|c|c|c|c|c|c|c|c|c|}
\hline \multirow{2}{*}{ Prácticas inclusivas en la convivencia escolar } & \multicolumn{2}{|c|}{ Cargo } & \multicolumn{2}{|c|}{ Edad } & \multicolumn{2}{|c|}{ Especialidad } & \multicolumn{2}{|c|}{ Tiempo servicio } \\
\hline & $\mathrm{F}$ & Sig & F & Sig & $\mathrm{F}$ & Sig & $\mathrm{F}$ & Sig \\
\hline 1. Actos de bienvenida al alumnado & 815 & 487 &, 430 & ,732 &, 851 &, 515 &, 534 & ,660 \\
\hline 2. Actos de despedida al alumnado & 1,734 & ,162 & 285 & 836 & 1,914 & ,095 & ,365 & ,778 \\
\hline 3. Actos de bienvenida al profesorado &, 546 & 651 & ,752 &, 523 & ,716 & ,612 & 1,420 & ,239 \\
\hline 4. Actos de despedida al profesorado &, 307 & 820 & 1,239 & 297 & 656 & ,658 & 2,049 & , 109 \\
\hline 5. Actos de bienvenida a las familias &, 383 & ,765 & ,294 &, 829 & 659 & ,655 & 2,320 & ,077 \\
\hline 6. Actos de despedida a las familias & ,993 & ,397 &, 565 & ,639 & 1,467 & ,203 & ,948 & ,419 \\
\hline 7. Actos de bienvenida al personal no docente & ,282 & ,838 & 1,277 & 284 & 899 & ,483 & 3,139 &, 027 \\
\hline 8. Actos de despedida al personal no docente & 410 & ,746 & 2,544 & ,058 &, 535 & ,750 & 1,352 & 259 \\
\hline 9. Actividades culturales & 2,220 & 088 & 3,227 & 024 & 078 & ,995 & 1,861 & ,138 \\
\hline 10. Actuaciones del centro con el entorno & 696 &, 556 & ,783 &, 505 & 802 &, 549 & 1,816 & ,146 \\
\hline $\begin{array}{l}\text { 11. Comprobación de la satisfacción del } \\
\text { alumnado }\end{array}$ & 667 &, 573 & 1,760 & 157 & 2,267 & ,051 & ,712 &, 546 \\
\hline $\begin{array}{l}\text { 12. Sentimientos de pertenencia del alumnado } \\
\text { al centro }\end{array}$ &, 450 & ,718 & , 102 &, 959 & ,700 & ,624 & 650 &, 584 \\
\hline $\begin{array}{l}\text { 13. Sentimientos de pertenencia del profeso- } \\
\text { rado }\end{array}$ & 1,115 &, 344 & ,996 &, 396 & , 187 & ,967 & 2,193 & ,091 \\
\hline 14. Sentimientos de pertenencia de las familias & 1,125 & 340 & 2,028 & ,112 & 1,021 & ,407 & 1,679 & ,173 \\
\hline $\begin{array}{l}\text { 15. Sentimientos de pertenencia del personal } \\
\text { no docente }\end{array}$ &, 519 & 670 & 1,251 & 293 & ,323 & 899 & 800 & ,495 \\
\hline 16. Empleo de fórmulas de cortesía &, 592 & ,621 &, 507 & ,678 & ,712 & ,615 & 1,470 & ,225 \\
\hline 17. Empleo de símbolos &, 024 & ,995 & 1,428 & ,236 & 1,536 & ,181 & 1,101 &, 350 \\
\hline 18. Uso de estrategias a la expulsión & 335 & 800 & 2,895 &, 037 & 441 & 819 & 175 &, 913 \\
\hline 19. Continuación del aprendizaje & 1,106 & ,348 & 857 & 465 & 2,310 & , 056 &, 573 & ,634 \\
\hline $\begin{array}{l}\text { 20. Se tiene en cuenta la baja autoestima del } \\
\text { alumnado }\end{array}$ & ,666 &, 574 &, 816 & 486 &, 359 & 876 & ,296 &, 828 \\
\hline $\begin{array}{l}\text { 21. Corrección conjunta de conductas inapro- } \\
\text { piadas }\end{array}$ &, 976 & ,405 & ,297 &, 828 & ,783 &, 563 & 1,203 & ,310 \\
\hline 22. Alumnado crea estrategias & ,235 & 872 & 2,089 & 104 & 1,692 & ,139 & 1,845 & ,141 \\
\hline $\begin{array}{l}\text { 23. Familias están de acuerdo con las normas } \\
\text { de convivencia }\end{array}$ &, 405 &, 749 & 3,275 &, 023 & ,689 & ,632 & 2,248 &, 085 \\
\hline
\end{tabular}

Fuente: Elaboración propia. 


\subsection{Prácticas inclusivas en la organización y funcionamiento del centro}

En esta dimensión se analizaron aquellas prácticas que, aun concerniendo a la organización y al funcionamiento del centro, inciden de forma directa en todas las prácticas inclusivas que se desarrollan en el centro mismo (ver tabla 4).

TABLA 4

PRÁCTICAS INCLUSIVAS EN LA ORGANIZACIÓN Y FUNCIONAMIENTO DEL CENTRO

\begin{tabular}{|l|c|c|c|}
\hline \multicolumn{1}{|c|}{ Organización y funcionamiento del centro } & Media & $\begin{array}{c}\text { Desvia- } \\
\text { ción típica }\end{array}$ & N \\
\hline 1. Conocimiento de la normativa & 4,12 & 0,875 & 173 \\
\hline 2. Al profesor novel se le facilita el PEC & 4,19 & 1,168 & 173 \\
\hline 3. Información sobre formación del profesorado & 4,28 & 0,891 & 173 \\
\hline 4. Eliminación de barreras arquitectónicas & 3,38 & 1,597 & 173 \\
\hline 5. Criterios comunes de organización espacial de las aulas & 3,92 & 1,21 & 173 \\
\hline 6. Criterios pedagógicos del horario & 4,04 & 1,553 & 173 \\
\hline 7. Formación aleatoria de los grupos & 4,31 & 1,579 & 173 \\
\hline 8. Agrupamientos flexibles como medida de AD & 4,39 & 1,404 & 173 \\
\hline 9. Participación de toda la comunidad & 4,02 & 1,086 & 173 \\
\hline 10. Información en distinta lengua a las familias & 3,97 & 2,572 & 173 \\
\hline 11. Oportunidades de las familias para participar & 4,1 & 1,012 & 173 \\
\hline 12. Coordinación entre las etapas & 3,98 & 1,078 & 173 \\
\hline 13. Oferta de actividades extraescolares & 4,25 & 0,817 & 173 \\
\hline 14. Medidas pedagógicas y expulsión & 4,81 & 2,095 & 173 \\
\hline 15. Organización del centro para la mejora & 4,57 & 0,96 & 173 \\
\hline
\end{tabular}

Fuente: Elaboración propia.

Los ítems $14\left(\overline{\mathrm{X}}=4^{\prime} 81\right)$ y $15\left(\overline{\mathrm{X}}=4^{\prime} 57\right)$ son los que más destacan en esta dimensión. Aunque en su conjunto los resultados se encuentran por encima de la media, estos son más bajos que los obtenidos en la dimensión analizada anteriormente, por lo que podemos deducir que las estrategias de organización y funcionamiento que influyen en la consecución de una educación más inclusiva no se encuentran sistematizadas plenamente.

El ítem 14, existen medidas pedagógicas para reintegrar a los estudiantes que han sido expulsados por motivos de disciplina, podría interpretarse que la formulación del mismo es incompleta, ya que el número de alumnos y alumnas que se expulsan en educación primaria no es significativo. Las medidas pedagógicas existen, pero no se aplican porque no es necesario.

En cuanto al ítem $15\left(\overline{\mathrm{X}}=4^{\prime} 57\right)$, el equipo directivo tiene claro que la organización del centro está en función de la mejora del aprendizaje de todos y cada uno de los alumnos y alum- 
nas, nos hace pensar que el profesorado entiende que los directivos tienen claro este extremo, porque, ¿qué otra razón puede existir que no sea esa para estar al frente de un centro educativo? No obstante, en relación al conjunto de ítems de esta dimensión y a los resultados obtenidos podría considerarse la respuesta a este último ítem más como un propósito u objetivo que como una realidad normativizada en los documentos del centro.

Una vez que se procedió al análisis de las medias y las desviaciones típicas, se aplicó un Análisis de Varianza a las variables sexo, lugar de trabajo y tutorización (ver tabla 5); en este caso, sólo se han hallado diferencias en torno a la variable lugar de trabajo, así destacamos las siguientes:

- Ítem 1. Todo el profesorado del centro conoce la normativa relativa a la atención a la diversidad $(\mathrm{F}=11.291, \mathrm{p}=0.001)$. Esta afirmación es realizada en mayor grado por el profesorado de la capital $(\bar{X}=4.41)$ que el de la provincia $(\bar{X}=3.96)$.

TABLA 5

ANÁLISIS DE VARIANZA DE LAS VARIABLES SEXO, LUGAR DE TRABAJO Y TUTORIZACIÓN. DIMENSIÓN ORGANIZACIÓN Y FUNCIONAMIENTO

\begin{tabular}{|c|c|c|c|c|c|c|}
\hline \multirow[b]{2}{*}{ Organización y funcionamiento del centro } & \multicolumn{2}{|c|}{ Sexo } & \multicolumn{2}{|c|}{ Lugar de trabajo } & \multicolumn{2}{|c|}{ Tutorización } \\
\hline & $\mathbf{F}$ & Sig & $\mathbf{F}$ & Sig & $\mathbf{F}$ & Sig \\
\hline 1. Conocimiento de la normativa & ,001 & ,974 & 11,291 & ,001 & ,000 & ,998 \\
\hline 2. Al profesor novel se le facilita el PEC & 1,286 & ,258 & 3,360 & 069 & 1,266 & ,262 \\
\hline $\begin{array}{l}\text { 3. Información sobre formación del profe- } \\
\text { sorado }\end{array}$ & 013 & ,910 & 820 & ,366 & ,405 &, 525 \\
\hline 4. Eliminación de barreras arquitectónicas & ,123 & ,726 & ,389 &, 534 & 2,731 & 100 \\
\hline $\begin{array}{l}\text { 5. Criterios comunes de organización } \\
\text { espacial de las aulas }\end{array}$ & ,206 & 651 & 4,860 & ,029 & 1,556 & 214 \\
\hline 6. Criterios pedagógicos del horario & 940 & ,334 & 130 & ,719 & 109 & 741 \\
\hline 7. Formación aleatoria de los grupos & ,249 & 618 & 4,271 & 040 & 2,829 & ,094 \\
\hline $\begin{array}{l}\text { 8. Agrupamientos flexibles como medida } \\
\text { de AD }\end{array}$ & ,105 & ,746 & 2,316 & 130 &, 018 & ,893 \\
\hline 9. Participación de toda la comunidad & 1,764 & ,186 & 5,600 & ,019 & , 028 & 867 \\
\hline $\begin{array}{l}\text { 10. Información en distinta lengua a las } \\
\text { familias }\end{array}$ &, 554 & ,458 & ,003 & ,957 & ,791 & ,375 \\
\hline $\begin{array}{l}\text { 11. Oportunidades de las familias para } \\
\text { participar }\end{array}$ & 087 & ,769 & ,003 & ,957 & 838 & ,361 \\
\hline 12. Coordinación entre las etapas & 2,396 & ,123 & 636 & 426 & ,416 &, 520 \\
\hline 13. Oferta de actividades extraescolares & 2,484 & 117 & 010 & ,921 & ,002 & ,964 \\
\hline 14. Medidas pedagógicas y expulsión & ,447 &, 505 & 2,991 & , 086 & ,005 & ,942 \\
\hline 15. Organización del centro para la mejora & ,005 & ,944 & 2,473 & ,118 & 1,246 & 266 \\
\hline
\end{tabular}

Fuente: Elaboración propia. 
- Ítem 5. El centro se plantea y asume criterios comunes respecto a la organización espacial de las aulas $(\mathrm{F}=4.860, \mathrm{p}=0.029)$. Los docentes de la capital $(\overline{\mathrm{X}}=4.20)$, frente a los de la provincia $(\bar{X}=3.78)$, son quienes más consideran que en su centro se adoptan criterios comunes en la organización espacial de las aulas.

- Ítem 7. Para formar los grupos-clase se tienen en cuenta los apellidos o cualquier otro criterio aleatorio $(\mathrm{F}=4.271, \mathrm{p}=0.040)$. Los maestros y maestras de la capital $(\overline{\mathrm{X}}=4.64)$ constatan más que los de provincia $(\bar{X}=4.13)$ la existencia de criterios aleatorios en la formación de los grupos de alumnos y alumnas.

- Ítem 9. El equipo directivo fomenta explícitamente la participación real de todos los sectores de la comunidad educativa más allá de la que establece la normativa $(\mathrm{F}=5.600$, $\mathrm{p}=0.019)$. Los docentes que ejercen en la capital $(\bar{X}=4.28)$, frente a los que lo

TABLA 6

ANÁLISIS DE VARIANZA DE LAS VARIABLES CARGO OCUPADO, EDAD, ESPECIALIDAD Y TIEMPO DE SERVICIO. DIMENSIÓN ORGANIZACIÓN Y FUNCIONAMIENTO

\begin{tabular}{|c|c|c|c|c|c|c|c|c|}
\hline \multirow{2}{*}{ Organización y funcionamiento del centro } & \multicolumn{2}{|c|}{ Cargo } & \multicolumn{2}{|c|}{ Edad } & \multicolumn{2}{|c|}{ Especialidad } & \multicolumn{2}{|c|}{ Tiempo servicio } \\
\hline & $\mathrm{F}$ & Sig & $\mathrm{F}$ & Sig & $\mathrm{F}$ & Sig & $\mathrm{F}$ & Sig \\
\hline 1. Conocimiento de la normativa & 1,999 & ,116 & 2,238 & ,086 & 1,272 & ,278 & 3,834 & ,011 \\
\hline 2. Al profesor novel se le facilita el PEC & 3,857 & 011 & 2,034 & 111 & 1,748 & ,126 & 4,111 & ,008 \\
\hline $\begin{array}{l}\text { 3. Información sobre formación del } \\
\text { profesorado }\end{array}$ & ,288 & 834 & 2,786 & ,056 & 2,993 &, 013 & 2,545 & ,058 \\
\hline $\begin{array}{l}\text { 4. Eliminación de barreras arquitectó- } \\
\text { nicas }\end{array}$ & ,962 & ,412 & 1,622 & , 186 & ,963 & ,442 & ,354 & ,786 \\
\hline $\begin{array}{l}\text { 5. Criterios comunes de organización } \\
\text { espacial de las aulas }\end{array}$ & 1,781 & ,153 & 3,665 & ,014 & 1,081 & ,373 & 6,062 & ,001 \\
\hline 6. Criterios pedagógicos del horario & 1,904 & 131 & 2,924 & , 060 & 1,901 & ,097 & ,391 &, 760 \\
\hline 7. Formación aleatoria de los grupos & ,682 &, 564 & 452 & ,716 & 1,007 & 415 & 847 & 470 \\
\hline $\begin{array}{l}\text { 8. Agrupamientos flexibles como medi- } \\
\text { da de } \mathrm{AD}\end{array}$ & 875 & ,455 & ,998 & ,395 & 1,288 & ,271 & 1,156 & ,328 \\
\hline 9. Participación de toda la comunidad & 1,490 & 219 & 1,048 & ,373 & 242 & 943 & 2,101 & ,102 \\
\hline $\begin{array}{l}\text { 10. Información en distinta lengua a las } \\
\text { familias }\end{array}$ & 772 &, 511 & ,986 & ,401 & 693 & 630 & ,373 & ,773 \\
\hline $\begin{array}{l}\text { 11. Oportunidades de las familias para } \\
\text { participar }\end{array}$ & ,719 &, 542 & ,122 & ,947 & ,631 & ,676 & ,277 & 842 \\
\hline 12. Coordinación entre las etapas & 3,458 & ,018 & 145 & ,933 & 1,380 & ,234 & 894 & ,446 \\
\hline 13. Oferta de actividades extraescolares & 1,401 & ,244 & 2,355 & ,074 & ,520 & ,761 & 1,087 & ,356 \\
\hline 14. Medidas pedagógicas y expulsión & 678 &, 567 & 2,136 &, 054 & 1,136 &, 343 & ,321 & ,901 \\
\hline $\begin{array}{l}\text { 15. Organización del centro para la } \\
\text { mejora }\end{array}$ & 1,253 & 292 & 3,975 & ,009 & ,805 & ,548 & 1,163 & ,330 \\
\hline
\end{tabular}

Fuente: Elaboración propia. 
hacen en la provincia ( $\bar{X}=3.88$ ), entienden que su equipo directivo favorece la participación de toda la comunidad educativa.

Asimismo, tras aplicar un Análisis de Varianza para las variables cargo ocupado, edad, tiempo de servicio y especialidad por el profesorado hemos encontrado determinadas diferencias significativas que a continuación se expresan en la tabla 6.

El Análisis de Varianza realizado a la variable cargo docente ha evidenciado diferencias significativas en cuanto a la información que recibe el profesorado que se incorpora por primera vez al centro respecto a los documentos del mismo $(\mathrm{F}=3.857, \mathrm{p}=0.011)$; en este caso, los coordinadores de los distintos proyectos educativos opinan que esta práctica se encuentra más generalizada $(\bar{X}=4.81)$ que el profesorado que no ocupa cargo ( $\overline{\mathrm{X}}=4.01)$; así como en la coordinación existente en el centro entre etapas educativas $(\mathrm{F}=3.458, \mathrm{p}=0.018)$, en esta ocasión, es el equipo directivo quien destaca esta coordinación $(\overline{\mathrm{X}}=4.5)$, frente al docente sin cargo $(\overline{\mathrm{X}}=3.94)$.

En lo que respecta a la edad del profesorado hemos hallado diferencias significativas en la consideración que tienen los docentes sobre la existencia de criterios comunes en la organización espacial de las aulas $(\mathrm{F}=2.902$, $\mathrm{p}=0.023)$ y en la concepción que tiene el equipo directivo sobre la organización del centro en pro de la mejora del aprendizaje de todo el alumnado $(\mathrm{F}=3.029, \mathrm{p}=0.019)$.

En el primer caso, el profesorado de entre 21 y 30 años $(\bar{X}=3.64)$ cree que la elaboración de dichos criterios se producen en menos ocasiones que los docentes entre 41 y 50 años $(\bar{X}=4,37)$. En el segundo caso, los docentes con una edad comprendida entre 21 y 30 años $(\bar{X}=4.26)$ son más escépticos sobre la concepción del equipo directivo acerca de la organización del centro y la mejora del aprendizaje de todo el alumnado que el profesorado con edades entre 41 y 50 años $(\bar{X}=4.79)$.

En relación con la especialidad del profesorado se aprecian diferencias en cuanto a la percepción del profesorado respecto a la facilitación de información sobre actividades formativas permanentes $(\mathrm{F}=2.993, \mathrm{p}=0.013)$, es el profesorado de educación primaria el que en menor medida lo considera $(\bar{X}=4.10)$, frente al profesorado de educación infantil que es el que más lo aprecia $(\bar{X}=4.70)$.

En cuanto al tiempo de servicio destacamos las siguientes diferencias significativas:

- El conocimiento de la normativa relativa a la atención a la diversidad por parte de todos los docentes del centro $(\mathrm{F}=3.834$, $\mathrm{p}=0.011)$; así, el profesorado con un tiempo de servicio menor o igual a 10 años considera que este conocimiento es menor en el centro $(\bar{X}=3.86)$ que el profesorado que ha ejercido la docencia entre 21 y 30 años $(\bar{X}=4.40)$.

- La facilitación de los documentos que regulan el centro educativo al profesorado que se incorpora por primera vez al mismo ( $\mathrm{F}=4.111, \mathrm{p}=0.008)$; en este sentido, el docente con 10 o menos años de servicio es el que considera que esta práctica no se encuentra tan generalizada $(\bar{X}=3.86)$ como opina el profesorado con un intervalo de docencia entre los 21 y 30 años $(\bar{X}=4.60)$.

- El planteamiento común del centro educativo sobre la organización espacial de las aulas $(\mathrm{F}=6.062, \mathrm{p}=0.001)$; así, se destacan diferencias en la percepción del profesorado con un tiempo de servicio comprendido igual o menor a 10 años $(\bar{X}=3.68)$ y el que cuenta con un tiempo de servicio entre 21 y 30 años $(\bar{X}=4.80)$. 


\section{DISCUSIÓN DE LOS RESULTADOSY CONCLUSIONES}

En el apartado anterior se han plasmado los resultados obtenidos de la información ofrecida por los docentes que han participado en el estudio, pudiéndose apreciar la existencia de diferencias estadísticamente significativas en muchos de los aspectos analizados. Teniendo presente estos resultados y tomando como referente el interrogante de investigación planteado al iniciar la investigación, podemos expresar las siguientes conclusiones:

Respecto a si encontramos diferencias en las prácticas docentes sobre una convivencia que nace de un concepto inclusivo en función de las variables que caracterizan al profesorado, podemos señalar que la convivencia desde una perspectiva inclusiva se manifiesta como una forma idónea para corregir los problemas que se derivan de la diversidad del alumnado. Pero en estas prácticas existen algunas diferencias en relación con las variables independientes, destacando la variable lugar de trabajo (Córdoba capital o provincia); en este sentido, los docentes de la capital son más conscientes y tienen un mayor conocimiento de las prácticas inclusivas en torno a la convivencia que los docentes de la provincia. La explicación podría encontrarse en que en los centros de la provincia existe menos conflictividad que en la capital; esto provoca que el profesorado de la capital necesite dar respuestas a los problemas de convivencia que se producen en sus centros y que éstas generen estrategias, técnicas, acuerdos, consenso en torno a los distintos aspectos que conforman la convivencia en los mismos.

En cuanto a si apreciamos diferencias en la organización y funcionamiento de los centros en función de las variables que identifican a los docentes de dichos centros, podemos comentar la existencia de diferencias estadísticamente significativas también en la variable lugar de trabajo, pues el profesorado de capital opina en mayor medida que el de provincia que en sus centros existe un conocimiento de la normativa relativa a la atención a la diversidad, una asunción de criterios comunes respecto a la organización espacial de las aulas, unos criterios aleatorios para formar los grupos-clase, así como un fomento de la participación de la comunidad educativa más allá de lo prescriptivo por parte del equipo directivo.

Asimismo, podemos apuntar que en la capital la organización de la convivencia se encuentra más sistematizada que en los centros de la provincia debido a un mayor tamaño de los centros y a necesidades de convivencia diferentes, además en la provincia el concepto de escuela sigue siendo el de un apéndice de la casa, con relaciones distintas entre las familias y los docentes. Estos aspectos son necesarios tenerlos presentes de cara a una intervención asesora en los centros de la provincia por parte de la Inspección Educativa.

La edad del profesorado constituye una variable que condiciona diferentes aspectos como la elaboración de criterios comunes en los colegios para la organización espacial de las aula y en la opinión del equipo directivo sobre la organización del centro como elemento esencial para mejorar el aprendizaje de todo el alumnado. Las diferencias se aprecian de forma más evidente entre intervalos de edades que exigen una mayor maduración personal y profesional, así como una visión personal de la educación inclusiva y las prácticas docentes y organizativas. 
En la variable tiempo de servicio se refleja que los maestros y maestras con menor experiencia en la enseñanza son más críticos con las prácticas que se llevan a cabo en el centro; de este modo, consideran que la normativa sobre atención a la diversidad no es muy bien conocida en el centro, así como que la facilitación de la normativa del centro al profesorado nuevo no está muy generalizada y la distribución espacial en el aula no se encuentra sustentada en criterios comunes, frente a lo que opina el profesorado de más edad.

La variable especialidad manifiesta diferencias significativas en cuanto a la información que ofrece el centro sobre la facilitación de información relativa a actividades formativas; de este modo, los docentes de educación infantil son los que entienden que esta información se distribuye en el centro sin ningún problema.

La ocupación o no de un cargo por parte de los docentes también muestra diferencias significativas respecto a la opinión sobre la entrega de documentación al profesorado que se incorpora por primera vez al centro; en este sentido, los coordinadores de proyectos opinan que esta práctica está más generalizada que el profesorado que no ocupa cargo. En lo relativo a la coordinación con otras etapas educativas, son los directivos los que creen que se hace en mayor medida que el profesorado sin cargo. Esta situación muestra la diferente perspectiva del profesorado al ejercer o no un cargo en cuanto a la convivencia y organización y funcionamiento de los centros.

A modo de reflexión final se puede decir, sin temor a equivocarnos, que la educación inclusiva que perseguimos implantar en los centros educativos, y que tendría que ser la clave para dar una respuesta ajustada a todos y cada uno de nuestros alumnos y alumnas, no deja de presentar rasgos característicos e importantes en los procesos educativos que se desarrollan en los centros de educación infantil y primaria de la zona norte de Córdoba.

Asimismo, si entendemos la inclusión como un proceso, se puede concluir que nos encontramos en el buen camino, aunque queda mucho por andar. No obstante, si consideramos el sentido más amplio del poliédrico término inclusión y de otros términos afines que hemos analizado con anterioridad, éste no es todavía entendido por una mayoría de los docentes y, por lo tanto, no se aplica como un principio sistémico, holístico y transformador.

Existen prácticas inclusivas, bien es cierto, y así nos lo demuestran los resultados obtenidos, pero inconexas al no responder a una concepción global de lo que debe significar la escuela y del papel que debe jugar en el contexto social en el que está enclavada. La investigación ha puesto de manifiesto, pues, la incorporación de prácticas inclusivas en los colegios de la zona norte de Córdoba; sin embargo, nos quedan ciertas dudas sobre la efectividad de las mismas, ya que las respuestas dadas por los docentes a los ítems planteados creemos que responden a lo "políticamente correcto". En un futuro avance de la investigación la observación sistemática de dichas prácticas y el desarrollo de diferentes focus group con el profesorado nos podrían llevar a un mayor conocimiento de la realidad inclusiva de los centros educativos.

Asimismo, pensamos finalmente, fruto de nuestra experiencia en las aulas, que la educación más o menos inclusiva en la enseñanza primaria dista bastante de la que se encuentra en Educación Secundaria; en este sentido, una posible línea de investigación 
más avanzada podría ser la comparación entre ambas etapas educativas con objeto de comprobar si nuestras percepciones se corresponden con la realidad de los centros.

En definitiva, esta investigación supone el inicio de un camino que entre todos tendremos que andar, y como decía el poeta "siempre en la mente has de tener a Ítaca. Llegar allá es tu destino."

\section{BIBLIOGRAFÍA}

Ainscow, M. y Miles, S. (2008). Por una educación para todos que sea inclusiva: ¿Hacia dónde vamos ahora? Perspectivas, XXXVIII, 1, 17-44.

Almeida, M. y Alberte, J.R. (2009). Las concepciones de los profesores y la respuesta a la inclusión en Lisboa. Santiago de Compostela: Universidad de Santiago de Compostela.

Arnaiz, P. (2000). Educar en y para la diversidad. En Actas del I Congreso Internacional de Nuevas Tecnologías y Necesidades Educativas Especiales "Nuevas Tecnologías, viejas esperanzas" (pp. 29-37). Murcia: Consejería de Educación y Universidades.

Blanco, R. (2008) Construyendo las bases de la inclusión y la calidad de la educación en la primera infancia. Revista de Educación, 347, 33-54.

Booth,T. y Ainscow, M. (2000). Index for Inclusion: Developing Learning and Participation in Schools. Bristol: Centre for Studies on Inclusive Education (CSIE).

Dyson, A. y Millward, A. (2000). Schools and special needs: issues of innovation and inclusion. London: SAGE Publications.

Echeita, G. y Sandoval, M. (2002) Educación inclusiva o educación sin exclusiones, Revista de Educación, 327, 31-48.

Halinen, I., Järvinen, R. (2008). En pos de la educación inclusiva. Perspectivas, XXXVIII, 1, 97-127.

LOGSE. Ley Orgánica 1/1990, de 3 de octubre, de Ordenación General del Sistema Educativo (Boletín Oficial del Estado número 238, de 4 de octubre de 1990).

LOCE. Ley Orgánica 10/2002, de 23 de diciembre, de Calidad de la Educación (Boletín Oficial del Estado número 307, de 24 de diciembre de 2002).

LOE. Ley Orgánica 2/2006 de Educación (Boletín Oficial del Estado número 106, de 4 de mayo de 2006).

Moberg, S. (2001). Opettajien näkemykset inklusiivisesta opetuksesta. En Murto, P. y Naukkarinen, A. \& Saloviita, T. (ed.). Inkluusion haaste koululle. Jyväskylä: PSkustannus 82-95.

Moliner, M. (2008). Condiciones, procesos y circunstancias que permiten avanzar hacia la inclusión educativa: retomando las aportaciones de la experiencia canadiense. Revista latinoamericana de educación inclusiva, 2, 41-60.

Moriña Díez, A. (2008). ¿Cómo hacer que un centro sea inclusivo?: Análisis del diseño, desarrollo y resultados de un programa formativo. Revista de Investigación Educativa, $26,2,521-538$.

Orden de 25 de julio de 2008, por la que se regula la atención a la diversidad del alumnado que cursa la educación básica en los centros docentes públicos de Andalucía (Boletín Oficial de la Junta de Andalucía número 167, de 22 de agosto de 2008). 
UNESCO. (1994). Conferencia Mundial sobre Necesidades Educativas Especiales: Acceso y Calidad. Salamanca (España), 10 de junio de 1994. Disponible en línea http:www. unesco.org/education/pdf/SALAMA E.PDF [Consultado el 25 de mayo de 2010].

Watkins, A. (ed.) (2007). Assessment in Inclusive Settings: Key Issues for Policy and Practice. Odense. Denmark: European Agency for Development in Special Needs Education.

Wehmeyer, M. L. (2009) Autodeterminación y la Tercera Generación de prácticas de inclusión. Revista de Educación, 349, 45-67.

\section{ANEXO I. CUESTIONARIO: DETECCIÓN DE PRÁCTICAS INCLUSIVAS EN CENTROS DE EDUCACIÓN PRIMARIA DE LA ZONA NORTE DE LA PROVINCIA DE CÓRDOBA}

\section{A. DATOS DE IDENTIFICACIÓN}

1. Sexo: Mujer $\square \quad$ Hombre $\square$

2. Edad: 21 a 30 años $\square \quad$ 31-40 años $\square \quad 41-50$ años $\square \quad 51$ a 60 años más de 60 años $\square$

3. Tiempo de servicio:

Menos de 1 año $\square \quad 1$ a 5 años $\square \quad 6$ a 10 años $\square \quad 11$ a 20 años $\square$

21 a 30 años $\square \quad$ más de 30 años $\square$

4. Lugar de trabajo: Córdoba capital $\square \quad$ Córdoba provincia $\square$

5. Especialidad:

Educación Primaria $\square \quad$ Educación Física $\square \quad$ Educación Musical $\square$

Lengua Extranjera $\square \quad$ Pedagogía Terapéutica $\square \quad$ Audición y Lenguaje $\square$

Educación Infantil $\square$

6. Cargo ocupado durante el presente curso académico.

Miembro del equipo directivo $\square$

Coordinación de Proyectos $\square$

Coordinación de ciclo $\square$

Sin cargo $\square$

7. Tutorización

Tutor/a $\square \quad$ No tutor/a $\square$ 


\begin{tabular}{|c|c|c|c|c|c|}
\hline B. CONVIVENCIA & 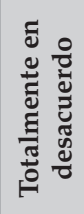 & 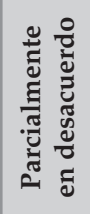 & 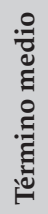 & 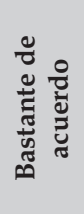 & 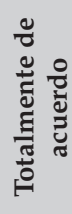 \\
\hline $\begin{array}{l}\text { 8. En tu centro hay actos sociales para dar la bienvenida al } \\
\text { alumnado }\end{array}$ & 1 & 2 & 3 & 4 & 5 \\
\hline $\begin{array}{l}\text { 9. En tu centro hay actos sociales para despedir al alumna- } \\
\text { do }\end{array}$ & 1 & 2 & 3 & 4 & 5 \\
\hline $\begin{array}{l}\text { 10. En tu centro hay actos sociales para dar la bienvenida al } \\
\text { profesorado }\end{array}$ & 1 & 2 & 3 & 4 & 5 \\
\hline $\begin{array}{l}\text { 11. En tu centro hay actos sociales para despedir al profeso- } \\
\text { rado }\end{array}$ & 1 & 2 & 3 & 4 & 5 \\
\hline $\begin{array}{l}\text { 12. En tu centro hay actos sociales para dar la bienvenida a } \\
\text { las familias }\end{array}$ & 1 & 2 & 3 & 4 & 5 \\
\hline $\begin{array}{l}\text { 13. En tu centro hay actos sociales para despedir a las fami- } \\
\text { lias }\end{array}$ & 1 & 2 & 3 & 4 & 5 \\
\hline $\begin{array}{l}\text { 14. En tu centro hay actos sociales para dar la bienvenida al } \\
\text { personal no docente }\end{array}$ & 1 & 2 & 3 & 4 & 5 \\
\hline $\begin{array}{l}\text { 15. En tu centro hay actos sociales para despedir al personal } \\
\text { no docente }\end{array}$ & 1 & 2 & 3 & 4 & 5 \\
\hline $\begin{array}{l}\text { 16. Si hay en tu centro alumnado de otras culturas, se reali- } \\
\text { zan actividades para el conocimiento de las mismas por } \\
\text { parte de las familias }\end{array}$ & 1 & 2 & 3 & 4 & 5 \\
\hline $\begin{array}{l}\text { 17. El centro educativo está implicado en actividades de las } \\
\text { instituciones de la localidad }\end{array}$ & 1 & 2 & 3 & 4 & 5 \\
\hline $\begin{array}{l}\text { 18. Se constata que después de varias semanas el alumnado } \\
\text { de nuevo ingreso se siente a gusto en el centro }\end{array}$ & 1 & 2 & 3 & 4 & 5 \\
\hline 19. El alumnado siente que es parte del centro educativo & 1 & 2 & 3 & 4 & 5 \\
\hline 20. El profesorado siente que es parte del centro educativo & 1 & 2 & 3 & 4 & 5 \\
\hline 21. Las familias sienten que son parte del centro educativo & 1 & 2 & 3 & 4 & 5 \\
\hline $\begin{array}{l}\text { 22. El personal no docente siente que es parte del centro } \\
\text { educativo }\end{array}$ & 1 & 2 & 3 & 4 & 5 \\
\hline $\begin{array}{l}\text { 23. Los distintos sectores de la comunidad educativa se sa- } \\
\text { ludan y despiden diariamente utilizando fórmulas de } \\
\text { cortesía }\end{array}$ & 1 & 2 & 3 & 4 & 5 \\
\hline $\begin{array}{l}\text { 24. El centro tiene en cuenta las culturas locales y los colec- } \\
\text { tivos de inmigración en los símbolos, documentos del } \\
\text { centro en distinto idioma y/o pictogramas que faciliten } \\
\text { las relaciones entre sus miembros }\end{array}$ & 1 & 2 & 3 & 4 & 5 \\
\hline
\end{tabular}




\begin{tabular}{|c|c|c|c|c|c|}
\hline B. CONVIVENCIA & 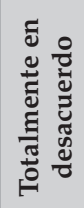 & 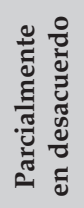 & 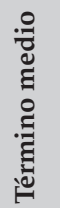 & 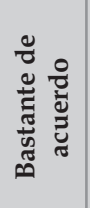 & 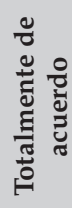 \\
\hline $\begin{array}{l}\text { 25. En el centro se utilizan distintas estrategias previas a la } \\
\text { sanción disciplinaria, tales como aula de convivencia, } \\
\text { mediación, etc. }\end{array}$ & 1 & 2 & 3 & 4 & 5 \\
\hline $\begin{array}{l}\text { 26. En el centro se considera que a pesar de la expulsión el } \\
\text { alumno puede continuar su aprendizaje }\end{array}$ & 1 & 2 & 3 & 4 & 5 \\
\hline $\begin{array}{l}\text { 27. Los docentes tienen en cuenta que la baja autoestima de } \\
\text { los alumnos y la insatisfacción de éstos puede ocasionar } \\
\text { problemas de conducta }\end{array}$ & 1 & 2 & 3 & 4 & 5 \\
\hline $\begin{array}{l}\text { 28. El profesorado de forma conjunta se siente responsable } \\
\text { en la corrección de las conductas del alumnado a través } \\
\text { de unos criterios claros y consensuados }\end{array}$ & 1 & 2 & 3 & 4 & 5 \\
\hline $\begin{array}{l}\text { 29. Se involucra al alumnado en la creación de estrategias } \\
\text { para prevenir y reducir la ruptura de la convivencia }\end{array}$ & 1 & 2 & 3 & 4 & 5 \\
\hline $\begin{array}{l}\text { 30. Las familias están de acuerdo con el profesorado con las } \\
\text { normas establecidas en el Plan de Convivencia }\end{array}$ & 1 & 2 & 3 & 4 & 5 \\
\hline \multicolumn{6}{|l|}{ C. ORGANIZACIÓN Y FUNCIONAMIENTO } \\
\hline $\begin{array}{l}\text { 31. Todo el profesorado del centro conoce la normativa rela- } \\
\text { tiva a la atención a la diversidad }\end{array}$ & 1 & 2 & 3 & 4 & 5 \\
\hline $\begin{array}{l}\text { 32. Al profesorado que se incorpora por primera vez al cen- } \\
\text { tro se le facilita el conocimiento del Proyecto Educativo } \\
\text { de Centro, el Reglamento de organización y funciona- } \\
\text { miento }\end{array}$ & 1 & 2 & 3 & 4 & 5 \\
\hline $\begin{array}{l}\text { 33. Se ofrece información variada al profesorado para poder } \\
\text { llevar a cabo una adecuada formación permanente en } \\
\text { distintos ámbitos }\end{array}$ & 1 & 2 & 3 & 4 & 5 \\
\hline $\begin{array}{l}\text { 34. Se han eliminado barreras arquitectónicas que dificul- } \\
\text { tan el acceso al centro y a sus distintas dependencias }\end{array}$ & 1 & 2 & 3 & 4 & 5 \\
\hline $\begin{array}{l}\text { 35. El centro se plantea y asume criterios comunes respecto } \\
\text { a la organización espacial de las aulas }\end{array}$ & 1 & 2 & 3 & 4 & 5 \\
\hline $\begin{array}{l}\text { 36. Los criterios para elaborar los horarios atienden única- } \\
\text { mente a aspectos pedagógicos consensuados y aproba- } \\
\text { dos por el claustro }\end{array}$ & 1 & 2 & 3 & 4 & 5 \\
\hline $\begin{array}{l}\text { 37. Para formar los grupos-clase se tienen en cuenta los ape- } \\
\text { llidos o cualquier otro criterio aleatorio }\end{array}$ & 1 & 2 & 3 & 4 & 5 \\
\hline $\begin{array}{l}\text { 38. Los agrupamientos flexibles son considerados como } \\
\text { una medida de atención a la diversidad }\end{array}$ & 1 & 2 & 3 & 4 & 5 \\
\hline
\end{tabular}




\begin{tabular}{|c|c|c|c|c|c|}
\hline B. CONVIVENCIA & 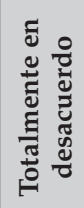 & 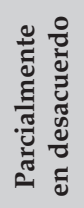 & 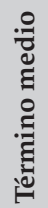 & 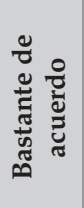 & 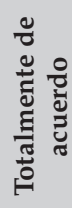 \\
\hline $\begin{array}{l}\text { 39. El equipo directivo fomenta explícitamente la participa- } \\
\text { ción real de todos los sectores de la comunidad educati- } \\
\text { va más allá de la que establece la normativa }\end{array}$ & 1 & 2 & 3 & 4 & 5 \\
\hline $\begin{array}{l}\text { 40. Las familias con otra lengua distinta a la nuestra reciben } \\
\text { información relativa a las líneas pedagógicas del centro } \\
\text { en su propia materna }\end{array}$ & 1 & 2 & 3 & 4 & 5 \\
\hline $\begin{array}{l}\text { 41. Las familias disponen de una variedad de oportuni- } \\
\text { dades para implicarse en las distintas actividades del } \\
\text { centro }\end{array}$ & 1 & 2 & 3 & 4 & 5 \\
\hline $\begin{array}{l}\text { 42. Hay coordinación eficaz y planificada entre Educación } \\
\text { Infantil y Primaria y entre Educación Primaria y Educa- } \\
\text { ción Secundaria Obligatoria }\end{array}$ & 1 & 2 & 3 & 4 & 5 \\
\hline $\begin{array}{l}\text { 43. En el centro hay una oferta suficientemente amplia de } \\
\text { actividades extraescolares para que pueda participar } \\
\text { todo el alumnado }\end{array}$ & 1 & 2 & 3 & 4 & 5 \\
\hline $\begin{array}{l}\text { 44. Existen medidas pedagógicas para reintegrar a los estu- } \\
\text { diantes que han sido expulsados por motivos de discipli- } \\
\text { na }\end{array}$ & 1 & 2 & 3 & 4 & 5 \\
\hline $\begin{array}{l}\text { 45. El equipo directivo tiene claro que la organización del } \\
\text { centro está en función de la mejora del aprendizaje de } \\
\text { todos y cada uno de los alumnos y alumnas }\end{array}$ & 1 & 2 & 3 & 4 & 5 \\
\hline
\end{tabular}

Fecha de recepción: 06 de febrero de 2011.

Fecha de revisión: 06 de febrero de 2011.

Fecha de aceptación: 16 de marzo de 2011. 